\title{
A fast method for the determination of ${ }^{210} \mathrm{~Pb}$ by LSC in liquid samples
}

\author{
Sampaio $^{\text {a C.S., Sousa }}{ }^{a}$ W.O., Dantas ${ }^{a}$ B.M. \\ ${ }^{a}$ CNEN/IRD/DIDOS, 22783-127, Rio de Janeiro, RJ, Brasil \\ camilla@ird.gov.br
}

\begin{abstract}
${ }^{210} \mathrm{~Pb}$ is a naturally occurring radionuclide, widely distributed on the earth's surface and can be incorporated by humans through food chain or directly by ingestion or inhalation in situations of occupational or accidental exposures. Because of its metabolic and dosimetric characteristics, ${ }^{210} \mathrm{~Pb}$ becomes an important isotope from the radiation protection point of view. This work presents the development of a methodology for the determination of ${ }^{210} \mathrm{~Pb}$ by liquid scintillation. It is the modification of a sequential analysis for naturally occurring radionuclides in environmental samples without the need of waiting for secular equilibrium to be achieved with ${ }^{210} \mathrm{Bi}$ that allows a faster determination of ${ }^{210} \mathrm{~Pb}$. The methodology has shown to be precise, stable and provides consistent results when evaluated according to the criteria established in the Brazilian Intercomparison Program promoted by the IRD. This technique can be applied to any sample after proper digestion and in liquid form.
\end{abstract}

Keywords: ${ }^{210} \mathrm{~Pb}$, liquid scintillation, in vitro bioassay. 


\section{INTRODUCTION}

${ }^{210} \mathrm{~Pb}$ is a product of the ${ }^{238} \mathrm{U}$ decay chain for which reliable bioassay techniques are of interest to a wide range of applications in the field of radiation protection since it presents one of the highest committed effective dose coefficients among naturally occurring radionuclides [1].

${ }^{210} \mathrm{~Pb}$ can be measured directly by gamma-spectrometry [2] or indirectly, through the determination of ${ }^{210} \mathrm{Po}$ by alpha-spectrometry [3] or measuring ${ }^{210} \mathrm{Bi}$ in a proportional counter [4]. By gamma spectrometry it is not necessary to achieve secular equilibrium but the technique presents poor sensitivity and self-absorption with a higher detection limit [2]. Alpha-spectrometry presents lower detection limit, but up to 6 months are necessary to achieve secular equilibrium between ${ }^{210} \mathrm{~Pb}$ and ${ }^{210} \mathrm{Po}$ [3]. Proportional counting also presents lower detection limit and the time for the secular equilibrium to be achieved between ${ }^{210} \mathrm{~Pb}$ and ${ }^{210} \mathrm{Bi}$ is lowered to 15 days. However, considering that it is a quantitative analysis and only total count will be taking into account, this technique can be highly affected by unknown interferences possibly present in the sample [4].

Liquid scintillation offers some advantages over other techniques, as it is not necessary to wait for secular equilibrium, offers detection limits comparable to $\alpha$ spectrometry and, in some cases, it is possible to detect the presence of sample interferences $[5,6]$.

Most of the techniques currently employed are based on the determination of lead after secular equilibrium is established with bismuth, which can be as low as 15 days. On the other hand, liquid scintillation allows the measurement of ${ }^{210} \mathrm{~Pb}$ directly as well as indirectly, after secular equilibrium with ${ }^{210} \mathrm{Bi}$ is reached.

This work presents a suspension gel method applied for faster determination of ${ }^{210} \mathrm{~Pb}$ by liquid scintillation based on simultaneous radiochemical separation of ${ }^{226} \mathrm{Ra}$ and ${ }^{210} \mathrm{~Pb}$, by direct measurement, without the need to wait for secular equilibrium with ${ }^{210} \mathrm{Bi}$ be achieved. This technique can be applied to any sample, after proper digestion, in liquid form in a $\mathrm{HNO}_{3} 1 \%$ matrix. 


\section{MATERIALS AND METHODS}

\subsection{Radiochemical procedure}

Radiochemical procedure is summarized in figure 1.

Figure 1: Radiochemical flow chart of the method.

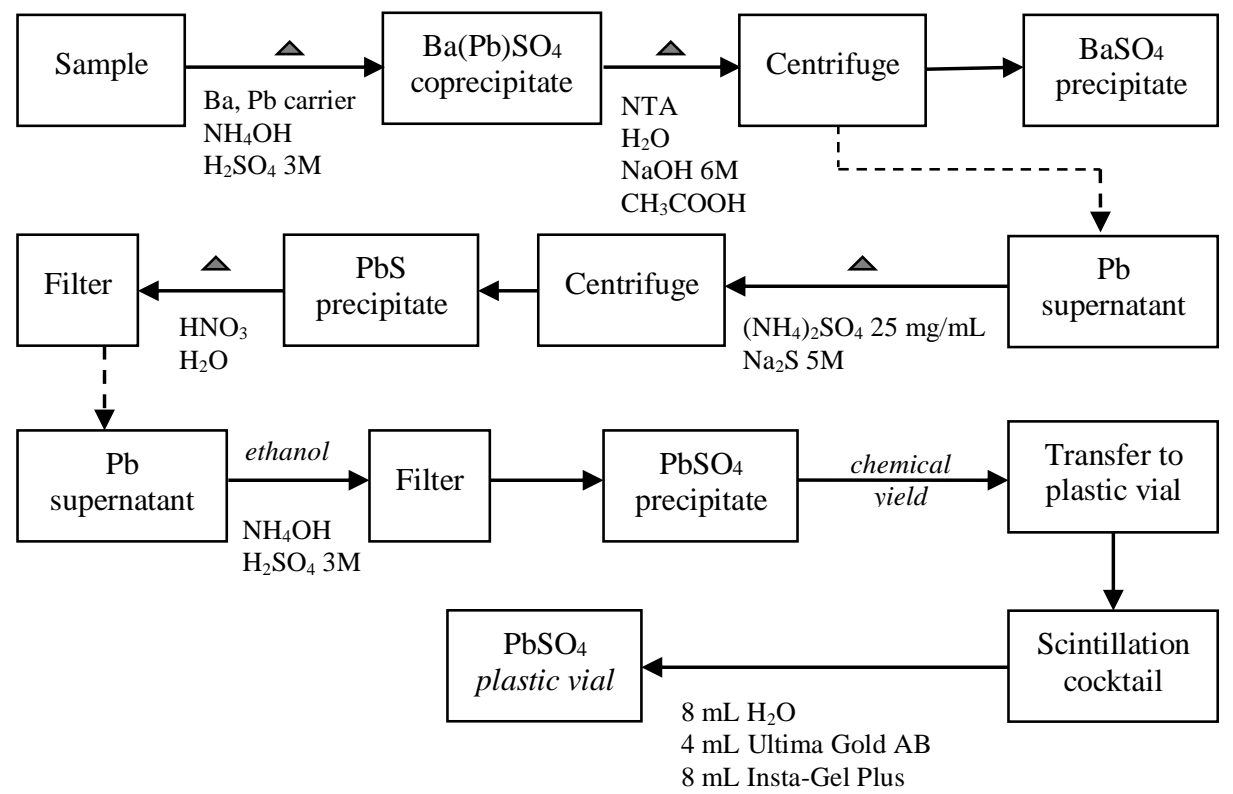

The method consists of a selective precipitation of barium and lead present in the sample [7] in form of sulphates.

It is a three-day step, the first step consisting of neutralizing the sample to $\mathrm{pH} 4.5$ - 5 (containing

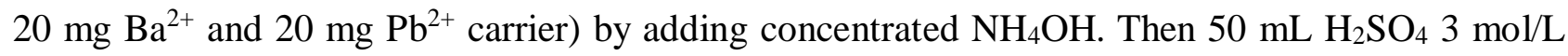
was added to the sample in order to precipitate simultaneously barium (and consequently radium) and lead in form of $\mathrm{BaSO}_{4}$ and $\mathrm{PbSO}_{4}$. At the second day, the supernatant was discarded and the precipitate re-dissolved using $2 \mathrm{~g}$ nitrilotriacetic acid (NTA), $30 \mathrm{~mL}$ distilled water and $7 \mathrm{~mL} \mathrm{NaOH}$ $6 \mathrm{~mol} / \mathrm{L}$. Barium (and radium) sulphate was precipitated with addition of glacial acetic acid until $\mathrm{pH}$ 4.5. At the third day, after centrifugation, $1 \mathrm{~mL} \mathrm{Na} 2 \mathrm{~S}$ was added to the supernatant in order to 
precipitate $\mathrm{PbS}$ with help of $5 \mathrm{~mL}\left(\mathrm{NH}_{4}\right)_{2} \mathrm{SO}_{4} 25 \mathrm{mg} / \mathrm{mL}$. The sample was centrifuged and supernatant discarded. To the black precipitate was added concentrated $\mathrm{HNO}_{3}$ and water becoming yellow with $\mathrm{Pb}$ in solution. The solution was filtrated with filter paper (Whatman 40) and neutralized with concentrated $\mathrm{NH}_{4} \mathrm{OH}$ until $\mathrm{pH} 4.5-5 . \mathrm{PbSO}_{4}$ is then precipitated by adding $1 \mathrm{~mL}$ $\mathrm{H}_{2} \mathrm{SO}_{4} 3 \mathrm{~mol} / \mathrm{L}$. The radiochemical yield was determined gravimetrically using stable $\mathrm{Pb}^{2+}$ as carrier and sample was analyzed by liquid scintillation. Analytical grade reagents were used throughout this work.

This technique chemical yield ranged from $60 \%$ to $80 \%(n=40)$, with an average value of $75 \%$.

\subsection{Equipment}

Samples were counted with a Quantulus 1220 low-background scintillation spectrometer (Perkin Elmer/Wallac). It is provided with the software WinQ (Windows software for controlling Wallac 1220 Quantulus v. 1.2) used to control counting parameters.

\section{3. $\alpha$ Interferences: calibration of the $\alpha / \beta$ discrimination system}

Quantulus 1220 is provided with a pulse shape analysis (PSA) circuit that distinguishes alpha from beta pulses which varies from 1 (all events classified as alphas) to 256 (all events classified as betas).

It was necessary to select appropriate pure $\alpha$ and $\beta$ emitters since interferences are not constant for all radionuclides. Based on previous works $[6,8],{ }^{99} \mathrm{Tc}$ and ${ }^{241} \mathrm{Am}$ were chosen to calibrate for $\alpha / \beta$ interferences. Two vials containing non-radioactive $\mathrm{PbSO}_{4}$ were prepared. ${ }^{99} \mathrm{Tc}$ was added in the first vial, and ${ }^{214} \mathrm{Am}$ in the second. The vials were counted for 5 minutes from PSA 5 to PSA 120 and the total interference was calculated. The optimum value for PSA threshold level was 75. This is the value that minimizes the interferences of an alpha emitter in the counting region of a beta emitter. 


\subsection{Calibration}

The counting protocol for the scintillation cocktail method was set to low coincidence bias, Alpha/Beta configuration, PSA threshold level of 75, with a counting time of 100 minutes.

Three water samples in nitric acid were spiked with known activities $(3.5 \mathrm{~Bq})$ of a ${ }^{210} \mathrm{~Pb}$ standard solution supplied by the National Laboratory of Ionizing Radiations Metrology (LNMRI). One non-spiked sample was processed as blank. The radiochemical procedure was applied to those four samples. Counting was performed daily up to 15 days after precipitation. Efficiency was then calculated as

$$
\varepsilon=\left(r_{s}-r_{b}\right) /(60 . A \cdot y)
$$

where $r_{s}$ and $r_{b}$ are the total and background count rates (cpm) in the corresponding window, $A$ is the activity of ${ }^{210} \mathrm{~Pb}$ standard solution added to the calibration source and $y$ the radiochemical yield.

The efficiency average value was calculated using least square fitting.

\subsection{Accuracy assessment}

Three samples of water from the Brazilian Intercomparison Program and one blank sample were prepared and analyzed applying the radiochemical procedure proposed in this work and the same calibration parameters. The counting time was set to 100 minutes. Relative bias and normalized deviation (D) value were calculated as

$$
D=(x-U) /(s u / \sqrt{ } n)
$$

Where " $x$ " is the value of the analytical measurement; " $U$ " is the reference value; "su" is the standard deviation of the reference value and; " $n$ " is the number of repetitions. As closer $|\mathrm{D}|$ value gets to 0 the better. The method is considered good when $|\mathrm{D}|<2.2 \leq|\mathrm{D}|<3$ is considered acceptable and if $|\mathrm{D}| \geq 3$ the method is considered out of control. This is the evaluation value adopted by the Brazilian Intercomparison Program according to [10] and [11].

The uncertainties and characteristic limits (decision threshold and detection limits) were determined according to International Standard ISO 11929 [9]. 


\section{RESULTS AND DISCUSSION}

\subsection{Calibration}

Figure 2 shows a spectrum corresponding to ${ }^{210} \mathrm{~Pb}+{ }^{210} \mathrm{Bi}$ one day after precipitation (in red) and fifteen days after precipitation (in green), when secular equilibrium is achieved.

Figure 2: ${ }^{210} \mathrm{~Pb}$ spectrum (channel $\left.x \mathrm{cpm}\right)$.

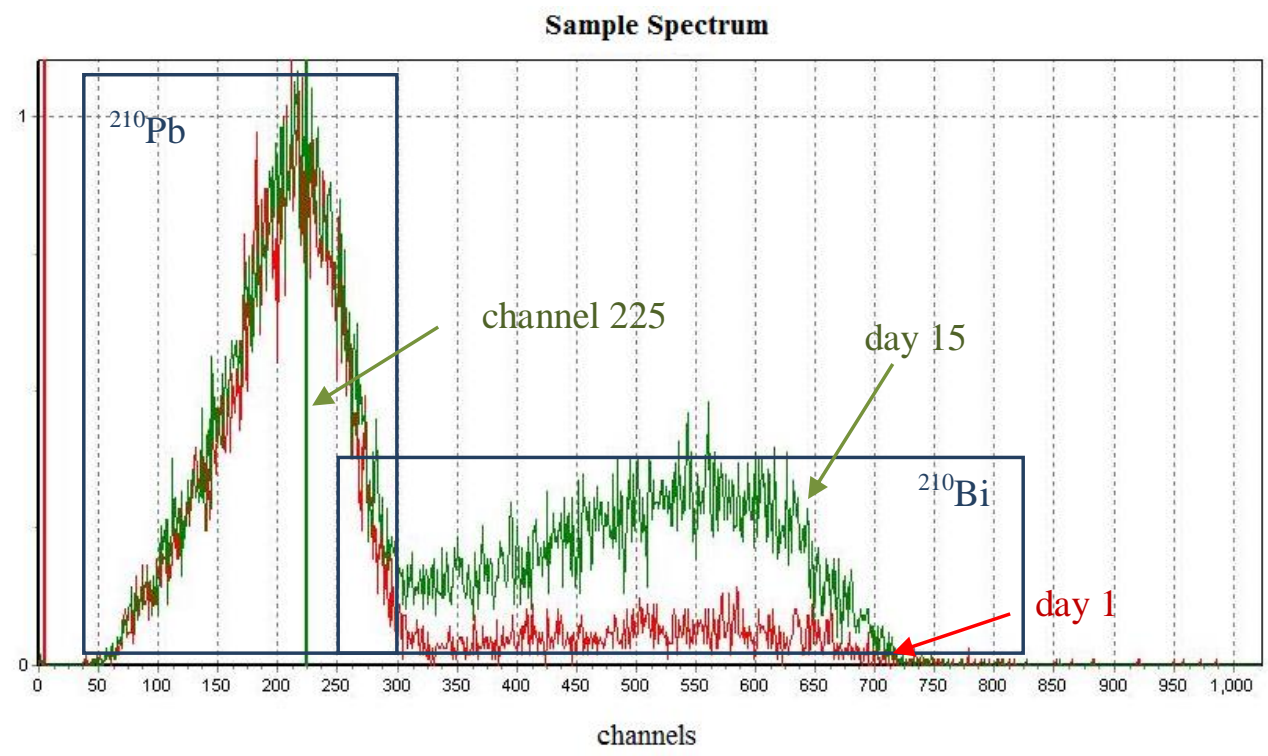

The first peak was from ${ }^{210} \mathrm{~Pb}$ contributions and the second from the ${ }^{210} \mathrm{Bi}$, where the growingup can be shown. Because both are beta emitters, they present broad pulse height that produces an overlap between their pulse spectra. Based on spectrum observation it was decided to work with the range of channels from 5 to 225 aiming to minimize the contributions of ${ }^{210} \mathrm{Bi}$, since the beta spectrum is continuous. The lower limit for the channel range was set at channel 5 to avoid the counts caused by chemiluminescence in cocktail, while the upper limit was set to channel 225, near half of the ${ }^{210} \mathrm{~Pb}$ spectrum, minimizing contributions of decay product in the region. Figure 3 shows 
the detection efficiency and its uncertainty as a function of days after precipitation for the channel range.

Figure 3: Scintillation cocktail efficiency curve up to 15 days after precipitation.

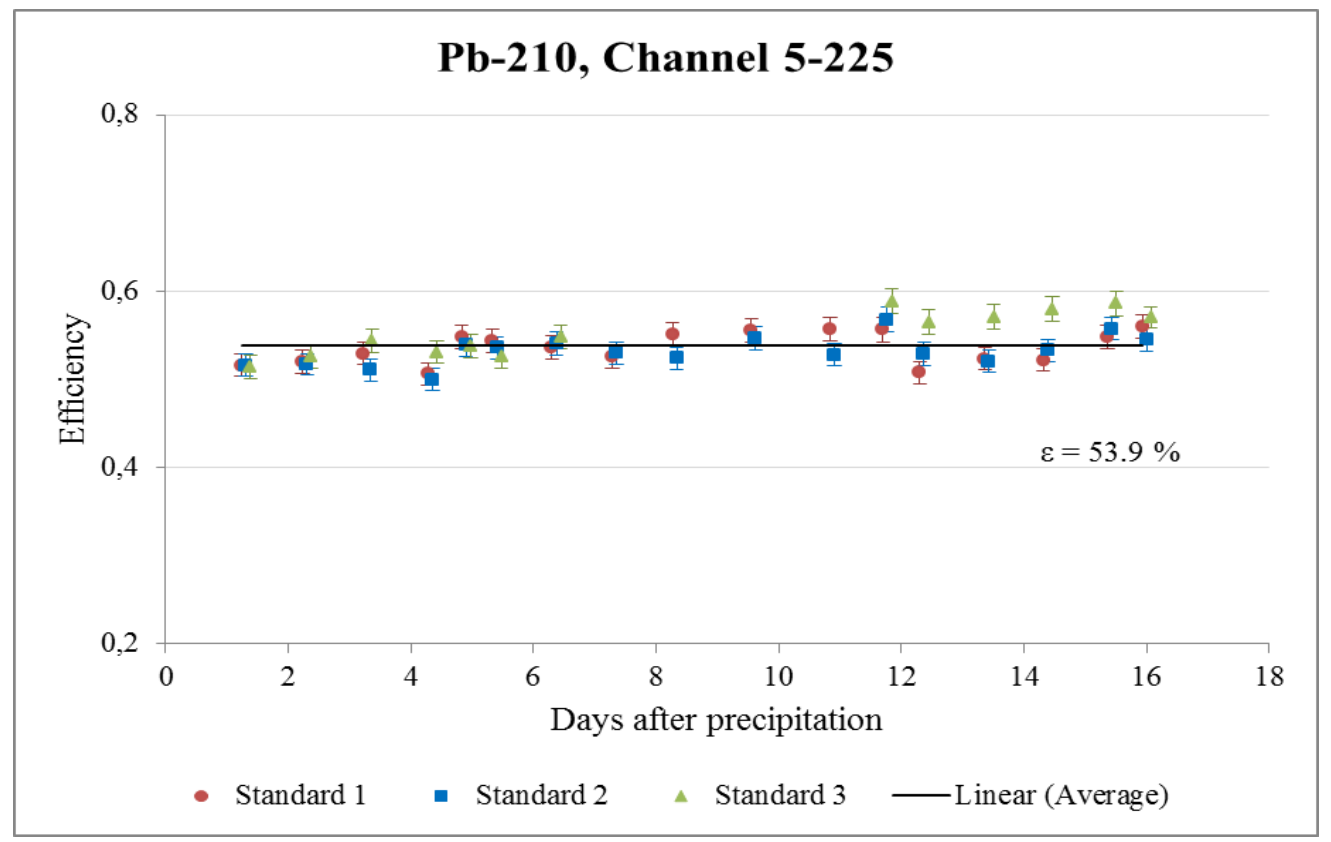

The average detection efficiency of $\varepsilon=53.9 \%$ was found to be independent of time by ANOVA test $(p=0.05)$, with a correlation of $R^{2}=0.33$. Such result relies on the fact that decay contributions are minimized when considering only ${ }^{210} \mathrm{~Pb}$ spectrum. There were no statistically significant differences between efficiency values found during time for the three standards and the average value after evaluated by $\mathrm{t}$-student test $(\mathrm{p}=0.005)$.

\subsection{Accuracy assessment}

Three aliquots of the sample from the Brazilian National Intercomparison Program were analyzed to assess the calibration. The vials prepared from each aliquot were measured at different times after the precipitation of lead. Table 1 presents the activities results using the proposed 
methodology for ${ }^{210} \mathrm{~Pb}$ in water, the different time after precipitation, reference value, normalized deviation (D) and relative bias. Activity uncertainties were calculated according to ISO11929 [9].

Table 1: Activity concentration of ${ }^{210} \mathrm{~Pb}$ obtained for different aliquots of the water reference sample 6116-EK27/0418.

\begin{tabular}{cccccc}
\hline Source & $\begin{array}{c}\text { Time after } \\
\text { precipitation } \\
(\text { days })\end{array}$ & $\begin{array}{c}\text { Analytical } \\
\text { activity } \\
\left(\mathbf{B q L} \mathbf{L}^{-\mathbf{1}}\right)\end{array}$ & $\begin{array}{c}\text { Reference } \\
\text { value } \\
\left(\mathbf{B q L} \mathbf{L}^{-\mathbf{1}}\right)\end{array}$ & $\begin{array}{c}\text { Bias } \\
(\boldsymbol{\%})\end{array}$ & $\mathbf{D}$ \\
\hline 1 & 0.3 & $0.895 \pm 0.042$ & & -1.6 & -0.14 \\
& 5.8 & $0.934 \pm 0.046$ & 2.7 & 0.23 \\
& 11.3 & $0.936 \pm 0.048$ & & 5.8 & 0.51 \\
2 & 1.6 & $0.920 \pm 0.041$ & & 1.1 & 0.10 \\
& 3.9 & $0.927 \pm 0.040$ & $0.910 \pm 0.182$ & 1.8 & 0.16 \\
& 5.8 & $0.905 \pm 0.044$ & & -0.5 & -0.03 \\
& 2.9 & $0.913 \pm 0.037$ & & 0.4 & 0.02 \\
& 4.9 & $0.890 \pm 0.041$ & & -2.2 & -0.11 \\
& 11.4 & $0.860 \pm 0.042$ & & -5.5 & -0.48 \\
\hline
\end{tabular}

Regardless of the period after precipitation, the results are within the acceptable reference value of ${ }^{210} \mathrm{~Pb}$ activity indicating that the proposed methodology is valid. This means that it is not necessary to wait 15 days for the secular equilibrium to be established between ${ }^{210} \mathrm{~Pb}$ and ${ }^{210} \mathrm{Bi}$. All samples are under the acceptable limit $(\mathrm{D}<2)$.

Detection limit was calculated according to ISO11929 [9] and ranged from 0.051 to $0.063 \mathrm{~Bq} / \mathrm{L}$. This value can be lowered by setting higher counting times since efficiency is independent of time.

\section{CONCLUSION}

In summary, according to the results of the Brazilian Intercomparison program, this technique is reliable when ${ }^{210} \mathrm{~Pb}$ is determined before secular equilibrium is established. 
It should be highlighted that it is a fast technique, considering the possibility of counting the sample since the first day after precipitation and can be used when there is a need for a rapid response for the determination of ${ }^{210} \mathrm{~Pb}$ activity levels.

\section{REFERENCES}

[1] LAURIA, D. C.; CARVALHO, L. L.; CONTI, C. C. Comparison of different methods for ${ }^{210} \mathrm{~Pb}$ determination in environmental samples. Advances in Liquid Scintillation Spectrometry LSC 2005, p. 211-216, 2006.

[2] SAN MIGUEL, E. G.; PÉREZ-MORENO, J. P.; BOLÍVAR, J. P.; GARCÍA-TENORIO, R.; MARTIN, J. E. ${ }^{210} \mathrm{~Pb}$ determination by gamma spectrometry in voluminal samples (cylindrical geometry). Nuclear Instruments and Methods in Physics Research Section A, v. 493 (1-2), p. 111-120, 2002.

[3] GARCÍA-ORELLANA, I.; GARCÍA-LEÓN, M. An easy method to determine ${ }^{210} \mathrm{Po}$ and ${ }^{210} \mathrm{~Pb}$ by alpha spectrometry in marine environmental samples. Applied Radiation and Isotopes, v. 56 (4), p; 633-636, 2002.

[4] GODOY, J. M.; MOREIRA, I.; WANDERLEY, C.; SIMÕES FILHO, F. F., MOZETO, A. A. An alternative method for the determination of excess ${ }^{210} \mathrm{~Pb}$ in sediments. Radiation Protection Dosimetry, v. 75 (1-4), p. 111-115, 1998.

[5] BLANCO, P.; LOZANO, J. C.; GÓMEZ ESCOBAR, V.; VERA TOMÉ, F. A simple method for ${ }^{210} \mathrm{~Pb}$ determination in geological samples by liquid scintillation counting. Applied Radiation and Isotopes, v. 60, p. 83-88, 2004.

[6] KIM, Y. -J.; KIM, C. -K.; LEE, J. -I. Simultaneous determination of ${ }^{226} \mathrm{Ra}$ and ${ }^{210} \mathrm{~Pb}$ in groundwater and soil samples by using liquid scintillation counter - suspension gel method. Applied Radiation and Isotopes, v. 54, p. 275-281, 2001.

[7] GODOY, J. M.; LAURIA, D. C.; GODOY, Ma. L. D. P.; CUNHA, R. P. Development of a sequential method for the determination of ${ }^{238} \mathrm{U},{ }^{243} \mathrm{U},{ }^{232} \mathrm{Th},{ }^{228} \mathrm{Th},{ }^{228} \mathrm{Ra},{ }^{226} \mathrm{Ra}$ and ${ }^{210} \mathrm{~Pb}$ in 
environmental samples. Journal of Radioanalytical and Nuclear Chemistry, v. 182, p. 165169, 1994.

[8] VILlA, M.; HURTADO, S.; MANJÓN, G.; GARCÍA-TENORIO, R. Calibration and measurement of ${ }^{210} \mathrm{~Pb}$ using two independent techniques. Radiation Measurements, v. 42, p. 1552-1560, 2007.

[9] ISO - International Organization for Standardization. Determination of the characteristic limits (decision threshold, detection limit and limits of the confidence interval) for measurements of ionizing radiation - Fundamentals and application. ISO 11929:2010, Geneva, 2010. 60p.

[10] NATRELA, M. G. Experimental Statistics. NBS Handbook n. 91, U.S. Department of Commerce, p. 3 - 8, NBS, 1963.

[11] JARVIS, N. A.; SIU, L. Environmental Radioactivity - Laboratory Intercomparison Studies Program. EPA-600/ 4-81-004, U.S. EPA, 1981. 